\title{
Oral Contraceptives and Venous Thromboembolism Consensus Opinion from an International Workshop held in Berlin, Germany in December 2009
}

\author{
Robert L Reid, Carolyn Westhoff, Diana Mansour, Corrine de Vries, Johan Verhaeghe, Ewald Boschitsch, \\ Anne Gompel, Martin Birkhäuser, Petr Křepelka, Petr Duliček, Ole-Erik Iversen, Marina Khamoshina, \\ Lucija Vrabič Dežman, Franca Fruzzetti, Anne Szarewski, Charlotte Wilken-Jensen, Daniel Seidman, \\ Risto Kaaja, Samuel Shapiro
}

\section{Workshop Participants/ Consensus Opinion Contributors}

Robert L Reid - Department of Obstetrics and Gynecology, Faculty of Health Sciences, Queen's University, Kingston, Ontario, Canada

Carolyn Westhoff - Department of Obstetrics and Gynecology, College of Physicians and Surgeons, Columbia University, New York, NY, USA

Diana Mansour - NHS Newcastle and North Tyneside, Community Health, New Croft Centre, Newcastle upon Tyne, UK

Corrine de Vries - Department of Pharmacy and

Pharmacology, University of Bath, Bath, UK

Johan Verhaeghe - Department of Obstetrics and Gynecology, Katholieke Universiteit Leuven, Leuven, Belgium

Ewald Boschitsch - Ambulatorium KLIMAX, Wien, Austria Anne Gompel - Service de Gynécologie, Université Paris Descartes, Paris, France

Martin Birkhäuser - Department of Obstetrics and Gynaecology, University of Berne, Base, Switzerland

Petr Krepelka - Institute for Care of Mother and Child, Podolske nabrezi, Prague, Czech Republic

Petr Duliček - Division of Clinical Haematology, University Hospital, Hradec Králové, Sokolská, Czech Republic

Ole-Erik Iversen - Institutt for Klinisk Medisin, Seksjon for Gynekologi og Obstetrikk, Kvinneklinikken, Haukeland Universitetssykehus, Bergen, Norway

Marina Khamoshina - Department of Obstetrics and Gynecology, RUDN/People Friendship University of Russia, Moscow, Russia

Lucija Vrabič Dežman - Gynaecological Clinic, Health Centre Kranj, Gosposvetska, Kranj, Slovenia

Franca Fruzzetti - Department of Obstetrics and Gynecology, Ospedale S Chiara, Pisa, Italy

Anne Szarewski - Cancer Research UK Centre for Epidemiology, Mathematics and Statistics, Wolfson Institute of Preventive Medicine, London, UK

Charlotte Wilken-Jensen - Region Sjælland, Gynækologiskobstetrisk Afdeling, Roskilde Sygehus, Køgevej, Roskilde, Denmark

Daniel Seidman - Department of Obstetrics and Gynecology, Sheba Medical Center, Tel-Hashomer, Sackler School of Medicine, Tel-Aviv University, Tel-Aviv, Israel

Risto Kaaja - Turku University, Satakunta Central Hospital, Pori, Finland

Samuel Shapiro - Department of Public Health and Family Medicine, University of Cape Town, Cape Town, South Africa

J Fam Plann Reprod Health Care 2010; 36(3): 117-122

Correspondence to: Professor Robert L Reid, Department of Obstetrics and Gynecology, Faculty of Health Sciences, Queen's University, Kingston, Ontario, Canada ON K7L 4V7.

E-mail: robert.reid@queensu.ca
Background and purpose of the workshop

Concern about the venous thromboembolism (VTE) risk of new hormonal contraceptive options shortly after their entry into the market has triggered a number of 'pill scares', each of which resulted in panic stopping of the formulations in question and a spike in unplanned pregnancies, yet with no subsequent reduction in VTE rates among women of reproductive age.

Perhaps the best example of a recent pill scare that resulted in enormous harm from a public health perspective was the 'third-generation pill scare' that occurred in many countries in Europe and around the world in 1995. At that time the new third-generation pills were promoted as being less androgenic and as possibly having fewer adverse effects on cardiovascular and metabolic parameters and thereby potentially being safer than existing pills.

Shortly after the introduction of these third-generation pills, reports of a possible increased risk of VTE began to appear. Such reports brought the progestogen component of these pills under scrutiny and inevitably a phenomenon known as 'stimulated reporting' occurred. Physicians with patients on these new pills were more likely to send their patients for assessment of any leg pain or swelling and more likely to report any VTE episodes to regulatory authorities because of heightened awareness of the possible risk. What followed was an international pill scare when regulatory authorities in a number of countries issued alerts about the possible increased risk of VTE with thirdgeneration pills. Panic stopping of pills by millions of women resulted in an abrupt and alarming rise in unplanned pregnancy as evidenced by sudden increases in deliveries and abortions, ${ }^{1-3}$ each with their attendant increased risks of VTE.

The history of this unfortunate episode is well documented. After class action lawsuits and lengthy trials, at which experts in epidemiology debated the findings, there emerged an awareness that studies examining VTE risks, in particular, required an understanding of the epidemiology of VTE and the possible biases that might systematically result in findings which diverged from the 'truth'.4,5 The precise effects of different hormonal contraceptives on the haemostatic system continue to be studied and debated 6,7 but because compelling data for an increased risk have not been demonstrated the lawsuits were ultimately thrown out ${ }^{8}$ and third-generation pills remain on the market and are widely prescribed today. ${ }^{9}$

In 2009, anecdotal reports of VTE episodes in women using an ethinylestradiol/drospirenone (EE/DRSP)-based oral contraceptive (Yasmin ${ }^{\circledR}$ ) were followed by publications with conflicting findings about the risk of VTE with this product. This led the manufacturer to invite experts in gynaecology, reproductive endocrinology, haematology and epidemiology to a workshop to critically review these recent publications to understand the reasons for divergent results and to produce a consensus statement about the likely comparative risk of this new formulation and other marketed products. Those contributing to the 
workshop critically appraised all relevant papers in a consistent manner, applying a standardised critical appraisal tool to ensure equity and consistency between appraisals of studies. ${ }^{10}$ This document is the resulting consensus opinion, drafted by all the experts invited to the workshop and unedited by the manufacturer's employees.

If certain combined oral contraceptives (COCs) carry a higher VTE risk than others, this needs to be clear so women can be advised accordingly and well-informed treatment decisions can be made. At the same time, scares founded on flawed study results that become driven by media and legal interests do not serve the public good. It is essential that the level of risk is determined through a bestevidence evaluation of available data and that balanced and informed decisions are made by considering both benefits and risks of contraceptive formulations.

\section{Oral contraceptives: balancing benefits and risks}

Modern COCs afford not only excellent contraception but also a variety of non-contraceptive benefits ranging from regulation and reduction of both menstrual bleeding and dysmenorrhoea to treatment of premenstrual syndrome, menstrual migraines, acne and hirsutism. Long-term benefits include reduced rates of endometrial and ovarian cancer. ${ }^{11}$

Serious side effects are rare occurrences in OC users. Modern COCs are well tolerated and adherence to prescribed regimens is generally excellent thus allowing women to postpone their pregnancies. By avoiding unplanned pregnancies, women reduce their exposure to serious vascular risks and flare-ups of systemic diseases that may occur during pregnancy.

\section{Venous thromboembolism (VTE)}

VTE remains a rare but potentially serious complication of COC use. This condition typically involves thrombosis in the deep veins of the legs or pelvis and the potential for pulmonary embolism, which has potentially fatal consequences. Known risk factors for VTE include advancing age, ${ }^{12}$ antiphospholipid antibodies and hereditary thrombophilia, 13,14 cigarette smoking, 15 surgical procedures, ${ }^{16}$ trauma, and immobility (such as that associated with travel or hospitalisation), ${ }^{17}$ obesity, ${ }^{18}$ and pregnancy and the peripartum period. 19,20

Quoted rates of VTE appear to have increased in the general population in the past decade from $1 / 10000$ woman-years for non-COC users to 4-5/10 000 womanyears during the reproductive years. ${ }^{21}$ This may in part reflect a true increase in VTE rates due to demographic trends such as increasing obesity but also reflects greater physician awareness, increased referral to hospitals and improvements in diagnostic precision (e.g. Doppler ultrasound).

Traditionally hormonal contraceptives were thought to double or triple the rate of VTE above the background rate. While a decade ago common teaching was that non-pill users had VTE rates of 1/10 000 woman-years and COC users had rates of 2-3/10 000 woman-years, modern data obtained through active surveillance have provided new insights into the true risks. Contemporary evidence suggests that VTE rates in non-pregnant, non-pill users of reproductive age are higher than previously thought about 4-5/10 000 woman-years in non-COC users 21 with an approximate doubling of risk into the range of 9-10/ 10000 woman-years for COC users. ${ }^{22}$

To keep the risks of VTE for COC users in perspective it is important to remember that the risk of a VTE in pregnancy is as high as $29 / 10000$ woman-years 22,23 and in the immediate postpartum period may reach 300-400/10 000 woman-years. 19,20 As one of the most widely used and effective contraceptive methods, the pill reduces rates of unplanned pregnancies and actually decreases the overall rate of VTE in the population in comparison to populations without access to effective contraception. ${ }^{24}$

Past research has shown that older, higher estrogen dose pills carried a slightly greater risk than currently marketed OCs, most of which contain less than $50 \mu \mathrm{g}$ EE. Sub-50 $\mu \mathrm{g}$ pills have a lower risk of VTE than pills with $50 \mu \mathrm{g}$ EE or more. ${ }^{25}$ While, in theory, greater reductions in the dosage of estrogen might further decrease the risk of VTE, this benefit has not been clearly established. A non-significant decrease in VTE was noted in the EURAS Study when comparing $30 \mu \mathrm{g}$ to $20 \mu \mathrm{g}$ EE-containing pills. ${ }^{22}$ Lidegaard also reported that "a reduction in oestrogen dose from $30-40 \mu \mathrm{g}$ to $20 \mu \mathrm{g}$ for OCs containing desogestrel or gestodene reduced the risk of venous thromboembolism by $18 \%$ ( $7 \%$ to $27 \%$ )". 26 However, the validity of the VTE diagnoses in the Danish registry has been questioned. ${ }^{27}$ Pills with $20 \mu \mathrm{g}$ EE or less have the potential to cause more breakthrough (unscheduled) bleeding and this may be a deterrent to consistent use for some women. ${ }^{28}$

Progestogen-only contraceptive methods have not been shown to increase the rate of VTE. ${ }^{29}$ Transdermal delivery of estradiol in hormone therapy for menopausal women may be associated with a reduced risk of $\mathrm{VTE}^{30}$ but available data do not suggest a benefit in terms of VTE risk when non-oral routes (i.e. transdermal and intravaginal) are used for delivery of combined hormonal contraception using EE. 31

Innovations in hormonal contraception in recent years have largely involved the use of new progestogens - not because there was a belief that these progestogens might influence VTE rates, but rather to harness the additional anti-androgenic benefits of some of these new products.

\section{Assessing VTE risks of new oral contraceptive products Surrogate markers for VTE risk}

Workshop participants considered the concept of 'estrogenicity' of OCs as measured by the differential impact of different estrogen and progestogen combinations on hepatic protein synthesis [primarily sex hormone binding globulin (SHBG) but also ceruloplasmin and corticosteroid binding globulin $(\mathrm{CBG})]$ and certain coagulation parameters [such as activated protein C (APC) resistance and total and free protein $S$ levels].

In postmenopausal women different routes of estrogen administration appear to be associated with different effects on hepatic protein synthesis and possibly different risks for VTE. $30,32,33$ The apparent differential effects of these routes of estrogen delivery led to the concept that 'estrogenicity' (as determined by hepatic production of SHBG in response to treatment) might predict risk for VTE.

Since the controversy about the VTE risk with thirdgeneration OCs surfaced in 1995, numerous investigators have evaluated differences in hepatic protein synthesis with different OC formulations to try to shed light on purported differences in VTE risk. Differential effects on hepatic proteins and APC resistance (which parallels the changes in SHBG) have been documented for different OC formulations, lending support to the concept of differential 'estrogenicity', with an implied association between thirdgeneration pills [which affect these parameters more than pills containing levonorgestrel (LNG)] and risk for VTE. While these findings have been used to try to explain why certain OC formulations might carry greater risks for 
VTE, 34 the clinical evidence to confirm such speculation is presently lacking. To be a valid surrogate marker for disease the marker must be validated in at least one prospective trial using both the surrogate marker and the true outcome ${ }^{35}$ and this has never been done. ${ }^{36}$ At present there are no validated surrogate markers for VTE risk associated with hormonal contraception.

\section{Premarketing indicators of VTE risk}

VTE remains one of the few serious adverse effects of contemporary hormonal contraception. Because VTE is so rare, valid information about the risks associated with a given pill cannot be adequately gleaned from premarketing research, which typically involves 1000-3000 women. As a result, any information on serious but rare side effects like VTE must come from postmarketing surveillance.

\section{Postmarketing surveillance: voluntary reporting of adverse reactions}

Many countries employ a voluntary surveillance system in which health care providers are asked to report unexpected and/or severe adverse reactions of drugs to regulatory authorities once these products enter the marketplace. Although such a system can alert regulatory authorities to rare unexpected side effects of a medication, the system is highly dependent on busy clinicians to recognise a potential adverse drug reaction and then to locate and complete the necessary forms when adverse events are encountered. Many times events go unreported and at times the same event may be reported by more than one physician. Media coverage of a particular concern is a well known cause for 'stimulated reporting' and self-referral among women using the product in question.

As a result, such a system is unable to provide valid information on the number of cases (numerators) for particular products. Since denominators (the number of women using a particular product) and the distribution of risk factors among the entire population of women prescribed a specific type of OC are unknown, voluntary case reports cannot provide valid information on comparative risks for rare but serious side effects.

\section{Observational studies and clinical trials}

For both observational studies and clinical trials the importance of risk factor assessment in populations under study cannot be overestimated. For example, if a product is perceived as having specific non-contraceptive benefits for obese women (DRSP may limit cyclic monthly weight gain and reduces acne and facial hair growth - both common worries for overweight women) then it may be preferentially prescribed to this population, which as a whole has a slightly higher risk of VTE. Such was the case with DRSP-containing pills as demonstrated in the noninterventional European Active Surveillance Study. In this large cohort study, health care providers were allowed to choose the OC they thought most appropriate in individual circumstances. Data analysis at the conclusion of the study showed that DRSP-containing pills were preferentially prescribed to obese women. ${ }^{22}$

One approach to obtaining information on rare events after marketing of a new product is to examine large databases to look for usage of a specific product and to establish linkages to complications like VTE. These techniques may be useful if the original data set collected information on age, body mass index (BMI), duration of use, family history of VTE, and so on, which are important independent risk factors for VTE. In the absence of quality data on such variables, it is impossible to exclude the possibility that a risk apparently associated with a specific $\mathrm{OC}$ is due to characteristics of the women to whom it was prescribed rather than a result of exposure to specific constituents of that pill. Databases, especially those developed for administrative purposes, may lack adequate validation of discharge diagnoses. Recent research has shown that conditions entered as VTE in an administrative database were often something else when testing was completed. 27

A valid comparison of VTE risk with different OCs must consider the fact that the risk for VTE is greatest in the first months of use and then falls closer to the background risk but remains elevated. ${ }^{22,37-39}$ This same effect was noted in the largest randomised clinical trial to examine VTE in menopausal women receiving hormone therapy at the time of menopause. ${ }^{40}$ Comparisons of the VTE risks between different OCs must account for recency of initiation of COCs and ensure that new users of one pill are truly being compared to new users of the other pill.

The type of research that is most likely to provide legitimate information on these rare risks involves a prospective approach with all subjects being new users of an OC. Careful follow-up by active surveillance (regular patient contact) and validation of all suspected cases (through examination of the medical records) is critical.

At the time of introduction of a new EE/DRSPcontaining COC into Europe, the manufacturer - with the approval of European regulatory authorities - initiated a study to compare the VTE risk of this new product with other marketed COCs in a 'real life' situation. Simultaneously, two database studies were carried out as well as a post hoc analysis of a case-control study set up with a different primary study aim. We provide an overview in the following section, in which each of the studies is described together with an overview of the study results, strengths, limitations and our resulting interpretation of the key findings.

\section{Recently published studies \\ European Active Surveillance Study (EURAS)}

The European Active Surveillance Study (EURAS) was conducted with the approval of European regulatory authorities and with oversight by an independent advisory board. This prospective, non-interventional, active surveillance study followed 59674 new users of different OCs for a total of 142475 woman-years of follow-up. Active follow-up resulted in a 'loss-to-follow-up' of only $2.4 \%$. All diagnoses were validated by review of medical records. The study demonstrated that DRSP-containing OCs were prescribed more often to heavier women and that despite this there was no difference in VTE rates between this new DRSP-containing OC and other marketed OCs. ${ }^{22}$

\section{Ingenix ${ }^{\mathrm{TM}}$ claims database}

A second large prospective study on the Ingenix ${ }^{\mathrm{TM}}$ claims database in the USA used a propensity (risk factor) scoring system to match new users of different pills according to baseline VTE risk. ${ }^{41,42}$ This study matched new OC prescriptions (Yasmin vs other pills in a 2:1 ratio) and validated the diagnoses by examination of medical records of all potential VTE episodes. No differences in VTE rates were found between DRSP-containing OCs and other marketed pills.

\section{Controversy over recent publications}

Publicity following reports of VTE episodes in users of Yasmin has once again ignited the debate about whether some feature of the new progestogen, drospirenone, may contribute to an increased risk of VTE compared to other 
pills. Two reports published in the British Medical Journal in 2009 appear, at first glance, to support this fear. Critical analysis of the two studies responsible for this adverse publicity, ${ }^{26,43}$ however, suggests that the conclusions could well have resulted from methodological flaws and/or misinterpretation of findings. 7,44

\section{Dutch Mega Study}

The Dutch Mega Study 43 was a study designed to evaluate environmental and genetic factors influencing VTE. The authors performed a substudy using a case-control approach to examine the effects of different OCs on VTE. Cases were identified from women with VTE attending an anticoagulation clinic. Controls were found in an unusual way, with many being partners of men seen in clinic and the remainder being found through random digit dialling. Duration of use information was not available on all women so it is not clear that all were new users, and women were not matched according to BMI. The authors showed hazard ratios for various OCs with wide and overlapping $95 \%$ confidence intervals (CIs) indicating no statistically significant difference in the VTE risk between DRSP-containing pills and other pills. Despite this they concluded that second-generation OCs were safer as far as VTE was concerned. In recent revisions to the Yasmin product label in the USA, the Food and Drug Administration (FDA) has concluded: "The number of Yasmin cases [in the Dutch Mega Study] was very small (1.2\% of all cases) making the risk estimates unreliable." 45

\section{Danish National Cohort Study}

The other study reporting increased rates of VTE with DRSP-containing and third-generation OCs was a large Danish National Cohort Study. ${ }^{26}$ Prescriptions of Danish women and subsequent hospital diagnostic codes for VTE were retrospectively examined between 1995 and 2005 in a number of interrelated databases maintained by the Danish national health service. This comprehensive data set included 3.3 million woman-years of OC use. The investigators identified 2045 OC-associated VTEs during this time period. In keeping with prior reports they found that the risk of VTE was greatest shortly after initiating $\mathrm{COC}$ use and was lowest with pills containing the lowest estrogen dosages. In contrast to the prospective studies reported above they found that DRSP-containing OCs and third-generation OCs (i.e. those containing desogestrel or gestodene) carried an increased risk of VTE compared to LNG-containing OCs.

Several significant methodological weaknesses have been identified since the publication of that report. ${ }^{44}$ First, detailed information on confounders such as obesity, surgery or trauma was not available for the analysis. This is important as in the Danish population there has been close to a three-fold increase in obesity in the past decade, and evidence from other research suggests that obese women are more likely to be prescribed DRSP-containing OCs.

In addition, the investigators had no information on OC use before 1995. Lidegaard et al. classified all LNG users in 1995 as 'short-term' users. In response to the criticism that this might have unfairly compared long-term LNG users to short-term users of DRSP-containing pills Lidegaard responded that "it was very unlikely that this small misclassification of short-term users starting their short-term use in the beginning of 1995 would have had a substantial influence on our estimates". 46 Others have estimated that as many as $60 \%$ of those LNG users classified as having 'short-term' exposure in 1995 were misclassified, and that these individuals should have been classified as 'long-term' users. ${ }^{47}$ Such a misclassification could have significantly biased results in favour of LNGcontaining COCs. Supporting the premise that the duration of time since initiation of COC use was misclassified for many LNG users was the unexpected finding that all OCs with the exception of those containing LNG showed the anticipated first-year elevation of VTE risk.

A recent publication from Severinsen and colleagues in Denmark suggests that the incidence of VTE could not reliably be assessed in the Danish registry. 27 These authors examined the same Danish registry used by Lidegaard's group, and after reviewing the medical records of 1135 patients with a registry diagnosis of VTE they could confirm the diagnosis in only $31 \%$ of cases referred from emergency rooms and in only $71 \%$ of women admitted to the ward for diagnostic testing. The Danish database was designed as an administrative database rather than as a medical research database. The diagnostic codes were primarily intended to capture costs related to hospitalisation. Many physicians were incorrectly entering a diagnostic code of VTE rather than the intended code of 'admitted for evaluation of possible VTE'.

The increased rate ratio of VTE with DRSP-containing OCs compared to LNG-containing OCs was 1.64 (95\% CI 1.27-2.10). Considering the potential methodological issues identified above, and with rate ratios that in epidemiological terms are very small (relative risks of 2 or less), it is extremely difficult to exclude bias or residual confounding as the explanation for the findings. $7,44,48,49$ The recent serious allegations about the validity of the VTE diagnostic codes in the Danish database throw into doubt any conclusions about VTE risk of different pills based on this source. The new US FDA-endorsed product labelling for Yasmin addresses the Lidegaard study and concludes: "The risk estimates may not be reliable because the analysis may include women of varying risk levels." 45

\section{Conclusions}

The highest quality scientific studies evaluating the risk of VTE in women of childbearing age show a risk of approximately 4-5/10 000 woman-years in those who do not use OCs. In the absence of reliable contraception, women of reproductive age face risks of VTE associated with pregnancy and the immediate postpartum period that reach 300-400/10 000 woman-years. Prospective observational studies have shown that all currently marketed COCs increase the risk of VTE to the range of 9-10/10 000 woman-years of use and that this risk is highest in the first months of use with a fall towards baseline risk thereafter. Modern OCs offer excellent contraceptive efficacy and good adherence due to their many non-contraceptive benefits.

Although VTE related to OC use is a rare event, future research should strive to reduce the VTE rate further. Clinical prediction models for incident VTE should be developed on the basis of clinical parameters (age, BMI, smoking, family history, etc.) or clinical parameters plus screening for genetic thrombophilia defects in women with a positive family history. Each of the thrombophilia tests should be subjected to a cost-effectiveness analysis. In addition, the value of the proposed biochemical markers of VTE in OC users (APC resistance, $\mathrm{SHBG}$, etc.) must be assessed in large clinical studies, and the assays need to be standardised by international consensus. Finally, the VTE risk associated with further therapeutic innovations (e.g. estradiol-based OCs, non-oral formulations, etc.) should be evaluated.

Individual adverse events (such as pulmonary embolism or stroke) in women on combined hormonal contraception, though rare, are extremely unfortunate and must always be taken seriously. Public health is best served 
when medical management is based on the highest level of scientific evidence and by carefully considering whether any increases in risk outweigh the benefits of treatment. For most women the very low absolute risks of serious sequelae are outweighed by the well-established benefits of hormonal contraception. Research has shown that individualised risk assessment remains an important tool to identify women at increased risk for VTE who might be better advised to use alternative forms of contraception. For most healthy women of reproductive age the benefits of COCs will outweigh the risks.

\section{Statements on funding and competing interests}

Funding The workshop from which this consensus opinion arose was convened by Bayer Schering. None of the invited workshop participants/contributing authors has received any funding in respect of preparation of this consensus opinion, which has been produced/published completely independently of Bayer Schering.

Competing interests The majority of the workshop participants/contributing authors will, at one time or another, have received sponsorship and/or funding from one or more manufacturers of contraceptive drugs and products.

\section{References}

1 Mills A. Combined oral contraception and the risk of venous thromboembolism. Hum Reprod 1997; 12: 2595-2598.

2 Goodyear-Smith A, Arroll B. Termination of pregnancy following panic-stopping of oral contraceptives. Contraception 2002; 66: 163-167.

3 Skjeldestad FE. Increased number of induced abortions in Norway after media coverage of adverse vascular events from the use of third-generation oral contraceptives. Contraception 1997; 55: 11-14.

4 Spitzer WO. The aftermath of a pill scare: regression to reassurance. Hum Reprod Update 1999: 5: 736-745.

5 Lewis MA, MacRae KD, Kuhl-Habichl D, Bruppacher R, Heinemann LA, Spitzer WO. The differential risk of oral contraceptives: the impact of full exposure history. Hum Reprod 1999; 14: 1493-1499.

6 Hennessy S, Berlin JA, Kinman JL, Margolis DJ, Marcus SM Strom BL. Risk of venous thromboembolism from oral contraceptives containing gestodene and desogestrel versus levonorgestrel: a meta-analysis and formal sensitivity analysis. Contraception 2001; 64: 125-133.

7 Dinger J. Oral contraceptives and venous thromboembolism: old questions revisited. J Fam Plann Reprod Health Care 2009; 35: 211-213.

8 Mackay J.XYZ \& Others v Schering Health Care Limited, Organon Laboratories Limited, John Wyeth \&Brother Limited. [2002] EWHC 1420(QB)

9 Spitzer WO. The 1995 pill scare revisited: anatomy of a nonepidemic. Hum Reprod 1997; 12: 2347-2357

10 Ciliska D, Thomas H, Buffett C. An Introduction to EvidenceInformed Public Health and a Compendium of Critical Appraisal Tools for Public Health Practice. February 2008. http://www.nccmt.ca/pubs/eiph_backgrounder.pdf [Accessed 27 May 2010]

11 American College of Obstetricians and Gynecologists (ACOG). Non-contraceptive Uses of Hormonal Contraception. ACOG Practice Guideline Number 110. January 2010. Obstet Gynecol 2010; 115: 206-218.

12 Silverstein MD, Heit JA, Mohr DN, Petterson TM, O'Fallon WM Melton LJ 3rd. Trends in the incidence of deep vein thrombosis and pulmonary embolism. A 25 year population based study. Arch Int Med 1998; 158: 585-593.

13 Levine JS, Branch DW, Rauch J. The antiphospholipid syndrome. N Engl J Med 2002; 346: 752-763.

14 Mohllajee AP, Curtis KM, Martins SL, Peterson HB. Does use of hormonal contraceptives among women with thrombogenic mutations increase their risk of venous thromboembolism? A systematic review. Contraception 2006; 73: 166-178.

15 Pomp ER, Rosendaal FR, Doggen CJM. Smoking increases the risk of venous thrombosis and acts synergistically with oral contraceptive use. Am J Hematol 2008; 83: 97-102.

16 Geerts WH, Pineo GF, Heit JA, Bergqvist D, Lassen MR Colwell CW, et al. Prevention of venous thromboembolism: the Seventh ACCP Conference on Antithrombotic and Thrombolytic Therapy. Chest 2004; 126: 338S-400S.

17 Chandra D, Parisini E, Mozaffarian D. Meta-analysis: travel and risk for venous thromboembolism. Ann Intern Med 2009; 151 180-190.

18 Pomp ER, le Cessie S, Rosendaal FR, Doggen CJR. Risk of venous thrombosis: obesity and its joint effect with oral contraceptive use and prothrombotic mutations. Br J Haematol 2007; 139: 289-296.

19 Ros HS, Lichtenstein P, Belloco R, Petersson G, Cnattingius S. Increased risks of circulatory diseases in late pregnancy and puerperium. Epidemiology 2001; 12: 456-460.

20 Pomp ER, Lenselink AM, Rosendaal FR, Doggen CJM. Pregnancy, the postpartum period and prothrombotic defects: risk of venous thrombosis in the MEGA study. J Thromb Haemost 2008; 6: 632-637.

21 Heinemann LAJ, Dinger JC. Range of published estimates of venous thromboembolism incidence in young women. Contraception 2007; 75: 328-336.

22 Dinger JC, Heinemann LAJ, Kuhl-Habich D. The safety of a drospirenone-containing oral contraceptive: final results from the European Active Surveillance study on Oral Contraceptives based on 142,475 women-years of observation. Contraception 2007; 75: 344-354.

23 Heit JA, Kobbervig CE, James AH, Petterson TM, Bailey KR, Melton LJ 3rd. Trends in the incidence of venous thromboembolism during pregnancy or postpartum: a 30-year population-based study. Ann Intern Med 2005; 143: 697-706.

24 Ory HW. Mortality associated with fertility and fertility control: 1983. Fam Plann Perspect 1983; 15: 57-63.

25 Gerstman BB, Piper JM, Tomita DK, Ferguson WJ, Stadel BV, Lundin FE. Oral contraceptive estrogen dose and the risk of deep venous thromboembolic disease. Am J Epidemiol 1991; 133: $32-37$.

26 Lidegaard Ø, Løkkegaard E, Svendsen AL, Agger C. Hormonal contraception and risk of venous thromboembolism: national follow-up study. BMJ 2009; 339: b2890.

27 Severinsen MT, Kristensen SR, Overvad K, Dethlefsen C, Tjønneland A, Johnsen SP. Venous thromboembolism discharge diagnoses in the Danish National Patient Registry should be used with caution. J Clin Epidemiol 2010; 63: 223-228.

28 Gallo MF, Nanda K, Grimes DA, Schulz KF. Twenty micrograms vs. $>20$ microg estrogen oral contraceptives for contraception: systematic review of randomized controlled trials. Contraception 2005; 71: 162-169.

29 Culwell KR, Curtis KM. Use of contraceptive methods by women with current venous thrombosis on anticoagulant therapy: a systematic review. Contraception 2009; 80: 337-345.

30 Canonico M, Plu-Bureau G, Lowe GD, Scarabin PY. Hormone replacement therapy and risk of venous thromboembolism in postmenopausal women: systematic review and meta-analysis. BMJ 2008; 336: 1227-1231.

31 Jick SS, Hagberg KW, Hernandez RK, Kaye JA. Postmarketing study of ORTHO EVRA and levonorgestrel oral contraceptives containing hormonal contraceptives with $30 \mathrm{mcg}$ of ethinyl estradiol in relation to nonfatal venous thromboembolism. Contraception 2010; 81: 16-21.

32 De Lignieres B, Basdevant A, Thomas G, Thalabard JC, Mercier-Bodard $\mathrm{C}$, Conard $\mathrm{J}$, et al. Biological effects of estradiol-17 beta in postmenopausal women: oral versus percutaneous administration. J Clin Endocrinol Metab 1986; 62: $536-541$.

33 Kroon UB, Silfverstolpe G, Tengborn L. The effects of transdermal estradiol and oral conjugated estrogens on haemostasis variables. Thromb Haemost 1994; 71: 420-423.

34 Alhenc-Gelas M, Plu-Bureau G, Guillonneau S, Kirzin JM, Aiach $\mathrm{M}$, Ochat $\mathrm{N}$, et al. Impact of progestagens on activated protein $\mathrm{C}$ (APC) resistance among users of oral contraceptives. $J$ Thromb Haemost 2004; 2: 1594-1600.

35 Fleming TR, DeMets DL. Surrogate end points in clinical trials: are we being misled? Ann Intern Med 1996; 125: 605-613.

36 Grimes DA, Schulz KF, Raymond EG. Surrogate end points in women's health research: science, protoscience and pseudoscience. Fertil Steril 2010; 93: 1731-1734

37 Suissa S, Blais L, Spitzer WO, Cusson J, Lewis M, Heineman L. First time use of newer oral contraceptives and the risk of venous thromboembolism. Contraception 1997; 56: 141-146.

38 Herings RM, Urquhart J, Leufkens HG. Venous thromboembolism among new users of different oral contraceptives. Lancet 1999; 354: 127-128.

39 Bloemenkamp KW, Rosendaal FR, Helmerhorst FM, Vandenbroucke JP. Higher risk of venous thrombosis during early use of oral contraceptives in women with inherited clotting defects. Arch Intern Med 2000; 160: 49-52.

40 Cushman M, Kuller LH, Prentice R, Rodabough RJ, Psaty BM, Stafford RS, et al.; for the WHI Investigators. Estrogen plus progestin and the risk of venous thrombosis. JAMA 2004; 292 : 1573-1580.

41 Seeger JD, Loughlin J, Eng PM, Clifford CR, Cutone J, Walker AM. Risk of thromboembolism in women taking 
ethinylestradiol/drospirenone and other oral contraceptives. Obstet Gynecol 2007; 110: 587-593.

42 Eng PM, Seeger JD, Loughlin J, Clifford CR, Mentor S, Walker AM. Supplementary data collection with case-cohort analysis to address potential confounding in a cohort study of thromboembolism in oral contraceptive initiators matched on claims-based propensity scores. Pharmacoepidemiol Drug Saf 2008; 17: 297-305.

43 Van Hylckama Vlieg A, Helmerhorst FM, Vandenbroucke JP Doggen CJM, Rosendaal FR. Effects of oestrogen dose and progestogen type on venous thrombotic risk associated with oral contraceptives: results of the MEGA case-control study. BMJ 2009; 339: b2921

44 Shapiro S, Dinger J. Risk of venous thromboembolism among users of oral contraceptives: a review of two recently published studies. J Fam Plann Reprod Health Care 2010; 36: 33-38.

45 US Food and Drug Administration (FDA). FDA monograph on physician labelling for Yasmin 28 tablets (drospirenone and ethinyl estradiol). http://www.accessdata.fda.gov/drugsatfda docs/label/2010/021098s017lbl.pdf [Accessed 27 May 2010].

46 Lidegaard $\mathrm{O}$. Risk of venous thromboembolism among users of oral contraceptives: a review of two recently published studies (Letter). J Fam Plann Reprod Health Care 2010; 36: 103-104.

47 Shapiro S, Dinger J. Risk of venous thromboembolism among users of oral contraceptives: a review of two recently published studies (Letter). J Fam Plann Reprod Health Care 2010; 36: 104-105.

48 Spitzer WO. Bias or causality: Interpreting recent evidence of oral contraceptive studies. Am J Obstet Gynecol 1998; 179: S43-S50.

49 Shapiro S. Causation, bias and confounding: a hitchhiker's guide to the epidemiological galaxy. Part 3: Principles of causality in epidemiological research: statistical stability, doseand duration-response effects, internal and external consistency, analogy and biological plausibility. J Fam Plann Reprod Health Care 2008; 34: 261-264.

\section{FACULTY OF SEXUAL \& REPRODUCTIVE HEALTHCARE MEMBERSHIP EXAMINATION}

The Membership Examination (MFSRH) consists of:

\section{- Part 1 Multiple Choice Question paper (MCQ)}

The London-based examination is held annually in April and October. Applications for the April examination must be received by 1 January. Applications for the October examination must be received by 1 July. The new syllabus for the Part 1 is on the Faculty website.

\section{$\square$ Evidence Based Commentary (EBC)}

Candidates can view the released topic and candidate guidance notes for EBC on the Faculty website. There is an absolute deadline of $\mathbf{3 1}$ August $\mathbf{2 0 1 0}$ to submit the EBC on this topic.

\section{$\square$ Part 2 Examination (CRQ, EMQ, OSCE)}

This 2011 all-day examination will consist of:

\section{- $\quad$ Critical Reading Question examination paper (CRQ) \\ - Extended Matching Question examination paper (EMQ) \\ - Objective Structured Clinical Examination (OSCE)}

Applications for the MFSRH Part 2 held in June 2011 must be received by 3 January 2011.

The new Part 2 Syllabus, Membership Examination Regulations and sample EMQs are on the Faculty website.

The qualification is subject to re-certification every 5 years.

For the current MFSRH Examination Regulations, information on all components of the MFSRH examination and application forms, please visit the Faculty of Sexual and Reproductive Healthcare website: www.fsrh.org (Training \& Exams and Membership Exam).

\section{JOIN THE PANEL OF MFSRH EXAMINERS}

The Faculty Examination Committee invites applications to join the panel of MFSRH Examiners for the Membership Examination. Applications are sought only from those able to fully commit to all examiner duties and who meet the following criteria:

- To be accredited Members of the Faculty and active clinically in the sphere of the Faculty or to be Clinicians, of equivalent status, with an interest in Sexual and Reproductive Healthcare but whose speciality is Genitourinary Medicine (GUM), Public Health Medicine, Gynaecology or Primary Care.

- To be able to show excellence in the quality of patient care, research skills or teaching skills relevant to the sphere of the Faculty.

- To hold or have held the Faculty Letter of Competence in Medical Education or equivalent.

Further information and the examiner CV application form are available on the Faculty website: www.fsrh.org (Training \& Exams, Membership Exam, MFSRH Examiners). The closing date for applications is 13 September 2010. The form should be sent to the Examination Secretary, Examinations, FSRH, 27 Sussex Place, Regent's Park, London NW1 4RG, UK. Tel: +44 (0) 207724 5629. Fax: +44 (0) 2077235333. 